\title{
'Our Failure of Empathy': Kevin Carter, Susan Sontag, and the Problems of Photography
}

\author{
Wai Kit Ow Yeong
}

In a discussion about images of war and suffering in Regarding the Pain of Others (2003), Susan Sontag remarks that the moral problem of the 'educated class' lies in 'our failure [...] of imagination, of empathy'. 'Given Sontag's interest in photography, a question arises: can photographs promote empathy? The role of photographs as aide-mémoires and testaments to reality suggests that such images are ideal tools for cultivating emotional identification with others. Yet the commoditization of photography also renders it banal, leading to what has been condemned as the opportunistic exploitation of images by consumerist bourgeois society, as well asdisturbingly - the inhibition of empathy in discourse and practice. Bearing the realities of our media-saturated age in mind, I seek to explore the role of photography in relation to empathy by examining the visual impact, psychological effects and emotional influence of photographic media. In particular, I ground my analysis by focusing on the case of a Pulitzer Prize-winning image by the late South African photojournalist Kevin Carter. ${ }^{2}$ Taken during the 1993 famine in Sudan, the photograph shows a starving Sudanese girl who collapsed on her journey to the nearest feeding centre. Keeling over, she almost touches the ground with her forehead. The most distressing element in the picture is that a vulture lurks behind her, sinisterly awaiting her death. Tragically, two months after receiving his Pulitzer Prize, Carter committed suicide in Johannesburg, at the age of $33 .^{3}$ In the light of Sontag's ideas, Carter's photograph can be seen as a cautionary case in point. We are alerted not only to the potential hazards of photography, but also to the photograph as an instantiation of the complexities involved when contemplating the qualities of visual media. Such complexities concern the lure of images, the nature of human suffering, and the abiding tensions experienced by viewers torn between apathy and empathy.

\section{The Visual Impact of Photography}

It is, generally speaking, self-evident how a photograph like Carter's may encourage emotional identification through the means of its visual impact. Viewing a photograph involves paying attention to its subject, and any attention, no matter how feeble, is usually preferable to ignorance and apathy. When Carter's photograph was first

\footnotetext{
${ }^{1}$ Regarding the Pain of Others (London: Penguin, 2003), 7.

${ }^{2}$ First featured in Donatella Lorch, "Sudan Is Described as Trying to Placate the West," New York Times, 26 March 1993, A3. Image accessible here: Alex Selwyn-Holmes, "Vulture Stalking a Child", Iconic Photos, 2009, accessed 1 June 2014, http://iconicphotos.wordpress.com/2009/08/12/vulturestalking-a-child/.

${ }^{3}$ Bill Keller, "Kevin Carter, a Pulitzer winner for Sudan photo, is dead at 33," New York Times, 29 July 1994, B8.
} 
published in the New York Times on 26 March 1993, the image sparked a loud global outcry, with hundreds of readers contacting the newspaper and demanding to know the ultimate fate of the girl who gave a distinct human image to the distant crisis in the Sudan (the paper reported that the girl had enough strength to walk away from the vulture, though it was unknown whether she reached the feeding centre). ${ }^{4}$ One could even speculate that the 'picture that made the world weep' may have done more to prompt donations to humanitarian organizations aiding Sudanese famine victims than a multitude of other articles or speeches during the time. ${ }^{5}$ In other words, societal obligations may conflict with professional duties - the costs of not providing immediate aid to individuals in distress need to be measured against the benefits of raising global awareness about the situation. ${ }^{6}$

As Sontag observes, 'A photograph passes for incontrovertible proof that a given thing happened. The picture may distort; but there is always a presumption that something exists, or did exist, which is what's in the picture. ${ }^{7}$ The photograph, as Roland Barthes declares, is a 'message without a code': while other arts like painting or theatre depend on a code of conventions, styles, connotations and symbols for their signifiers to produce meaning, the photograph — or at least the press photograph — is unique in that it is self-sufficient as a 'perfect analogon' of reality. ${ }^{8}$ In terms of semiotic theory in the tradition of Charles S. Peirce, the photograph serves not just as an index that points to or correlates with an external object, but also as an icon that bears a direct physical resemblance to 'the scene itself, the literal reality'. ${ }^{9}$ To a large extent, the viewer's sense of shock and moral outrage derives from the function of the photograph as such an image of reality, confirming the veracity of the horrors witnessed and implying the urgency of action needed to remedy the situation.

The relation between photography and empathy, however, remains problematic. To begin with, it is unclear whether a photograph depicting suffering kindles sympathy or empathy. The Oxford English Dictionary defines empathy as the 'power of projecting one's personality into (and so fully comprehending) the object of contemplation'. ${ }^{10}$ Two separate but related elements of empathy can be observed here-projection of the self and comprehension of the other. Empathy is not sympathy; it is not about feeling sorry for others, but about feeling 'into them'. It is the displacement of the ego from the centre of one's consciousness, involving the broadening of one's understanding that results from the adoption of another's perspective. For some viewers of Carter's photograph, or of any image of suffering, the victim may still be Other; we see her pain but cannot feel it. Conceivably, viewers may be guilty of what Sontag describes as a 'failure of empathy', an inability to extend our emotional identification beyond the confines of the self.

\footnotetext{
${ }^{4}$ Lorch, "Sudan Is Described as Trying to Placate the West".

${ }^{5}$ Ibid.

${ }^{6}$ Yung Soo Kim and James D. Kelly, "Public Reactions toward an Ethical Dilemma Faced by

Photojournalists: Examining the Conflict between Acting as a Dispassionate Observer and Acting as a 'Good Samaritan',' Journalism and Mass Communication Quarterly, 87, no. 1 (2010): 23.

${ }^{7}$ On Photography (London: Penguin, 1977), 5.

${ }^{8}$ Roland Barthes, "The Photographic Message," in A Barthes Reader, ed. Susan Sontag (New York: Hill and Wang, 1983), 196.

${ }^{9}$ Ibid.

10 "empathy, n.", OED Online, 2014, Oxford University Press, http://www.oed.com/view/Entry/61284?redirectedFrom=empathy (accessed 1 June 2014).
} 


\section{Inhibiting Empathy}

Carter's 1993 photograph has been widely recognized as one of the most discussed and controversial examples that have highlighted ethical dilemmas about whether photojournalists should photograph or help their suffering subjects. ${ }^{11}$ Indeed one of the main responses that the image triggers in viewers may not be empathy but rather horror and disgust directed at the photographer. Viewers may question his ethics for capturing the image instead of rendering assistance to the victim. As the St. Petersburg Times (Florida) argued, many might regard Carter as 'a predator, another vulture on the scene', especially when 'adjusting his lens to take just the right frame of her suffering'. ${ }^{12}$ As widely reported in the media, Carter found himself embroiled in a severe and heated controversy centred on his iconic image symbolizing Africa's anguish. ${ }^{13}$ Carter was subjected to the same criticism levelled at many photojournalists who are often burdened with 'the reputation of being indifferent to the human suffering they frame in their viewfinders'. ${ }^{14}$ While some critics commended his picture for raising awareness about the 1993 famine via 'the indelible image of a starving Sudanese child', most lambasted Carter for not carrying the girl to the feeding centre (or simply feeding her himself). ${ }^{15}$ Some even accused him of deliberately taking full advantage of the girl's plight for personal gain. ${ }^{16}$

Yet Carter's experience when taking the photograph was harrowing and traumatic even while he was obligated to maintain a professional distance. It was reported that after capturing his image, Carter had chased the bird away, waiting until the girl resumed her journey to the centre. ${ }^{17}$ As recounted in an obituary piece in TIME magazine, Carter had penned a suicide note which included the confession: 'I am haunted by the vivid memories of killings \& corpses $\&$ anger $\&$ pain . . . of starving or wounded children'. ${ }^{18}$ Eventually, two months after he was awarded his Pulitzer Prize, he committed suicide by carbon monoxide poisoning in Johannesburg. ${ }^{19}$ The photojournalist - motivated by the need for professional objectivity-seems to have been genuinely distressed by the horrors he witnessed, experiencing what Sontag has called 'an assault on the sensibility of the viewer'. ${ }^{20}$ The excruciating anguish and guilt that he felt was the price he paid for belonging to a profession that rewards the ability to maintain dispassionate composure in the face of nightmarish misery and devastation.

\footnotetext{
${ }^{11}$ Yung Soo Kim and James D. Kelly. "Photojournalist on the Edge: Reactions to Kevin Carter's Sudan Famine Photo." Visual Communication Quarterly 20, no. 4 (2013): 208.

${ }^{12}$ Reena Shah Stamets, "Were his priorities out of focus?", St Petersburg Times (Florida), 14 April 1994, A1.

${ }^{13}$ Keller, "Kevin Carter, a Pulitzer winner for Sudan photo, is dead at 33."

${ }^{14}$ John L. Hulteng, The Messenger's Motives: Ethical Problems of the News Media (Englewood Cliffs, NJ: Prentice-Hall, 1985), 171.

${ }^{15}$ Frank Van Riper, "Pulitzer Pictures: Capturing the Moment," Washington Post, http://www.washingtonpost.com/wp-srv/photo/galleries/essays/001229.htm (accessed 17 October 2014).

${ }^{16}$ Greg Marinovich and Joao Silva, The Bang-Bang Club: Snapshots from a Hidden War (New York: Basic Books, 2000).

${ }^{17}$ Scott Macleod, "The Life and Death of Kevin Carter," TIME 144, no. 11 (1994), http://content.time.com/time/magazine/article/0,9171,981431-1,00.html (accessed 1 June 2014).

${ }^{18}$ Ibid.

${ }^{19}$ Riper, "Pulitzer Pictures: Capturing the Moment."

${ }^{20}$ Regarding the Pain of Others, 40.
} 
The danger is that the camera itself might inhibit empathy in a photographer by encouraging the prioritization of images above individuals. The urge that it provokes is not to aid others but to record their agony. Sontag's insights in On Photography (1977) seem uncannily applicable to Carter's case:

Photographing is essentially an act of non-intervention. Part of the horror of such memorable coups of contemporary photojournalism as the pictures of a Vietnamese bonze reaching for the gasoline can, of a Bengali guerrilla in the act of bayoneting a trussed-up collaborator, comes from the awareness of how plausible it has become, in situations where the photographer has the choice between a photograph and a life, to choose the photograph. The person who intervenes cannot record; the person who is recording cannot intervene. ${ }^{21}$

If Carter's actions aptly illustrate just such 'an act of non-intervention', Sontag helps to explain just why he never rendered direct assistance to the girl. The act of photographing seems to inculcate a psychological conception of the self as observer rather than agent, such that even the photographer's mind can be so closely allied with the camera to the extent that 'any intervention is out of the question'. ${ }^{22}$ Crucially, Sontag suggests that taking pictures is not just a sign of passivity and inaction, but a gesture that at least implicitly reinforces the status quo. To photograph is 'to be in complicity with whatever makes a subject interesting [...] including, when that is the interest, another person's pain or misfortune'. ${ }^{23}$ According to Sontag, the photographer thus risks succumbing to a kind of Schadenfreude, of unconscious gratification after seizing the opportunity to capture precious images even at the expense of others. This is not to assert, however, that all photographers who witness atrocities and do not intervene necessarily reflect a lower degree of empathy than those who do. Particular circumstances of the situation need to be taken into account: for instance, photographers may not be able to aid suffering victims without risking their own safety (as in the case of an Associated Press photographer who captured images of a man believed to be a Zulu spy being killed by a mob of African National Congress supporters). ${ }^{24}$ Similarly, Carter had been warned never to touch famine victims, who may have communicable diseases. ${ }^{25}$ The point is that the use of the camera contributes to situations of inaction and non-intervention, during which the impulse to empathize can often rest in uneasy tension with the desire to record footage of gripping events.

Images of suffering may also counter-intuitively hinder viewers' emotional identification. In an age marked by the proliferation of images, the constant coverage of photographs of calamities may desensitize viewers, as the torments of others have been converted into what has been called 'infotainment', or the enhancement of information-based content with entertainment value in order to attract audiences. ${ }^{26}$ Sontag points precisely to this trend:

Photographs shock insofar as they show something novel. Unfortunately, the ante keeps getting raised - partly through the very proliferation of such images of horror. [...] To suffer is one thing;

\footnotetext{
${ }^{21}$ On Photography, 11-12.

${ }^{22}$ Ibid., 12.

${ }^{23}$ Ibid.

${ }^{24}$ Sue O'Brien, "Eye on Soweto: A Study of Factors in News Photo Use," Journal of Mass Media Ethics 8, no. 2 (1993): 69.

${ }^{25}$ Riper, "Pulitzer Pictures: Capturing the Moment."

${ }^{26}$ Arthur Kleinman and Joan Kleinman, "The Appeal of Experience; The Dismay of Images: Cultural Appropriations of Suffering in Our Times," Daedalus 125, no. 1 (1996): 1.
} 
another thing is living with the photographed images of suffering, which does not necessarily strengthen conscience and the ability to be compassionate. It can also corrupt them. Once one has seen such images, one has started down the road of seeing more-and more. Images transfix. Images anesthetize. ${ }^{27}$

Carter's photograph is a relative latecomer in the long history of disaster images that have inundated the consciousness of viewers. The plethora of press photographs in the mass media means that the standards for newsworthiness become harder and harder to meet due to viewers' overexposure to such images, numbing their capacity for empathy. Consider Werner Bischof's pictures of Indian famine victims in the early 1950s, or images of emaciated Biafrans taken by Don McCullin in the early 1970s, just to list a few examples that Sontag mentions. ${ }^{28}$ Photographs of death have been circulated and re-circulated to the point of saturation, resulting in what the writer J. G. Ballard has described as the viewer's 'death of affect'. ${ }^{29}$ Due to the media's 'unbearable replay of a now familiar atrocity exhibition', ever-increasing doses of images are required to trigger the same emotional response, leading one 'down the road of seeing more-and more'. ${ }^{30}$ Society's insatiable appetite for these pictures becomes a kind of substance abuse, 'the most irresistible form of mental pollution'. 31

Furthermore, if we accept Marshall McLuhan's dictum that 'the medium is the message', it seems conceivable that the dominance of the Internet in our time has only intensified photography's anesthetizing effect. ${ }^{32}$ When viewing print media, the viewer can at least register the physical existence of the photograph as ink on paperthere is a sense of presence, trace, or reality about the printed photograph which may in turn subtly suggest the actuality of the event depicted and invite deeper reflection about it. But when viewing a photograph in a virtual medium, the viewer can register no physical presence. Instead, images become fleeting displays, trivialized as pop-ups, hyperlinks, and various digital distractions that flicker across webpages - such photographs are really just ephemeral pixels on a screen, subject to greater organizational needs and commercial demands. This haunting virtual landscape, as a system of meaning rendered meaningless by being interminably mutable, seems not unlike the world described by Jean Baudrillard, according to whom the play of 'simulation' has absorbed and consumed society. ${ }^{33}$ Barthes also seems to anticipate this phenomenon in Camera Lucida (1980) when he censures consumerist bourgeois society for reducing photographs to mere market commodities, banalizing and fetishizing them in fields like advertising. ${ }^{34} \mathrm{He}$ comments that 'we live according to a generalized image-repertoire [...] What characterizes the so-called advanced societies is that they today consume images and no longer, like those of the past, beliefs' ${ }^{35}$ In the modern image-consuming age, the tragic irony is that photographs intended to arouse empathy end up resulting in indifference; the emotional identification we are meant to feel when viewing the image is undercut by the impulse to sweep it aside.

\footnotetext{
${ }^{27}$ On Photography, 19-20.

${ }^{28}$ Ibid., 19.

${ }^{29}$ J.G. Ballard, "Some Words About Crash!," Foundation 9 (1975): 45.

${ }^{30}$ Sontag, On Photography, 19.

${ }^{31}$ Ibid., 24.

${ }^{32}$ Understanding Media: The Extensions of Man (New York: McGraw-Hill, 1964), 9.

${ }^{33}$ Simulacra and Simulation, trans. Sheila Glaser (Ann Arbor, MI: University of Michigan Press, 1981), 79.

${ }^{34}$ Camera Lucida, trans. Richard Howard (New York: Hill and Wang, 1981; repr., London: Vintage, 2000), 118.

${ }^{35}$ Ibid., 118-19.
} 


\section{The Influence of Photographic Media}

It is tempting, then, to assume that viewers' lack of emotional identification is simply the fault of the media. Surely, it seems, it is only the media's sensationalizing of photographs for commercial profit that has inured viewers to images of suffering. But perhaps the situation is more complex. Our 'failure of empathy' also stems from the ways in which our exposure to the medium of photography itself has influenced our emotional responses. The significance of such exposure is further deepened given the ubiquity of camera phones in the twenty-first century, which means that a substantial proportion of viewers in most modern societies are themselves amateur photographers. ${ }^{36}$ Contemporary viewers benefit from, contribute to, and extend the field of photography in ways unimaginable mere decades ago. An everyman armed with a camera phone is now a potential photojournalist. Sontag observes that contemporary photography has an intrinsically democratic quality, especially when it comes to capturing press photographs of noteworthy events, because modern technology allows untrained amateurs to produce images not inferior to those created by experienced professionals. ${ }^{37}$ One definitive example that Sontag offers to elucidate the point is the famed Here Is New York exhibition, featuring photographs of the September $11^{\text {th }}$ attacks, of which some of the most widely acclaimed images were taken by passers-by. ${ }^{38}$ Another instance is the 2004 Indian Ocean tsunami, which killed about 230,000 people in fourteen countries: people at the scene, many of whom were using camera phones, were the main source of footage for media outlets. ${ }^{39} \mathrm{Such}$ examples demonstrate the ways in which press photographs often owe their creation to chance and happenstance, as well as the extent to which photography has permeated the consciousness of modern societies.

This process of permeation seems to have had at least two major effects. Firstly, photography may have changed how viewers perceive people. Sontag perceives 'something predatory in the act of taking a picture', such that ' $[\mathrm{t}] \mathrm{o}$ photograph people is to violate them, by seeing them as they can never see themselves [...]; it turns people into objects that can be symbolically possessed' ${ }^{40}$ If, as she puts it, the camera is 'a sublimation of the gun' (a persuasive metaphor, given that the user of either device simply has to 'aim, focus, and shoot'), the act of photographing a person is 'a sublimated murder - a soft murder, appropriate to a sad, frightened time'. ${ }^{41}$ The risk is that the subject of a photograph becomes objectified, trivialized, effectively snuffed out - falling prey to our voyeuristic avarice for images. Instead of treasuring people, viewers may ascribe a greater value to photographs, which after all are 'memento mori' and 'the inventory of mortality', as it is this connection between death and photography that 'haunts all photographs of people'. ${ }^{42}$ Secondly, photography may have influenced how viewers perceive time itself. The 'omnipresence of cameras' fosters the idea that, as Sontag contends, 'time consists of interesting events, events worth photographing'. ${ }^{43}$ Like the iconic 1972 image of the naked South Vietnamese

\footnotetext{
${ }^{36}$ Stuart Jeffries, "The rise of the camera-phone", Guardian, 8 January 2010, accessed 1 June 2014, http://www.theguardian.com/technology/2010/jan/08/stuart-jeffries-camera-phones.

${ }^{37}$ Regarding the Pain of Others, 25.

${ }^{38}$ Ibid., 24-25.

39 "The rise of the camera-phone".

${ }^{40}$ On Photography, 14.

${ }^{41}$ Ibid.

${ }^{42}$ Ibid., 15, 70.

${ }^{43}$ Ibid., 11.
} 
girl sprayed by American napalm, running towards the camera screaming in agony with arms outstretched, Carter's photograph captures a mere 'privileged moment, turned into a slim object'. ${ }^{44}$ The pictured event gains 'a kind of immortality (and importance) it would never otherwise have enjoyed'-like all photographs, the image offers 'a neat slice of time', a frozen still dispossessed of its historical and sociopolitical context. ${ }^{45}$ Repeated exposure to photographs may consequently encourage a fragmented, atomized view of reality.

Yet this hardly means that photography has doomed humanity to emotional atrophy. It may be conceded that from disaster images alone, one simply cannot tell the full story behind the victims, which may present a difficulty for some viewers seeking to establish emotional identification with them. But although an explanatory narrative cannot be derived from a single image, it is perhaps unnecessary for viewers to seek such narratives in the first place. In the case of Carter's photograph, various thorny questions abound. Who was responsible for the girl's plight? Were there any aid agencies that could have come to her rescue? The point is that the details of the story which explain the physical circumstances of the starving child are largely irrelevant; what matters is that the girl was suffering. The facts of the particular situation, laid bare by the image, trump any generalizing, historicizing narrative. As Sontag remarks, 'A photograph is supposed not to evoke but to show. ${ }^{46}$ By particularizing the figures who suffer under the oppressive weight of forces beyond their control, photographs of such victims can alert us to the reality that photographic subjects are not archetypes but individuals, deeply deserving viewers' empathy.

Photography is thus, to borrow the words of poet Geoffrey Hill in a discussion about language, 'both a blessing and a curse, but in the right hands it can mediate within itself, thereby transforming blessing into curse, curse into blessing'. ${ }^{47}$ The key issue here is not merely how photographs are taken but how they are interpreted, applied, and employed to prompt social action. Donna Ferrato, a photographer of domestic violence, recounts an occasion involving a couple that she had been photographing for some time: as she was present when the man was just about to hit his wife, she managed to photograph precisely the moment when he assaulted the woman. ${ }^{48}$ Her instinct was 'to get the picture first', before intervening by grabbing the man's arm and preventing further abuse. ${ }^{49}$ Ferrato defends her photographic instinct by emphasizing the benefits her work could potentially engender in terms of public awareness. Faced with the dilemma about 'whether to take a picture or defend the victim', she reflects that if she 'chose to put down [her] camera and stop one man from hitting one woman', she would 'be helping just one woman', whereas if she captured the image, she 'could help countless more'. ${ }^{50}$ Carter's legacy remains similarly exemplary. By taking his controversial image, he alerted viewers to the thousands of famine victims who were not photographed, but who nonetheless deserved the public attention that his photojournalism ensured. Rather than

\footnotetext{
${ }^{44}$ Ibid., 18.

${ }^{45}$ Ibid., 11, 17.

${ }^{46}$ Regarding the Pain of Others, 42.

47 "The Eloquence of Sober Truth," in Collected Critical Writings, ed. Kenneth Haynes (Oxford: Oxford University Press, 2008), 341.

48 "'I was gutted that I'd been such a coward': Photographers who didn't step in to help", Guardian, 2012, accessed 1 June 2014, http://www.theguardian.com/media/2012/jul/28/gutted-photographerswho-didnt-help.

${ }^{49}$ Ibid.

${ }^{50}$ Ibid.
} 
condemning his efforts, we can acknowledge that the onus is perhaps on viewers to respond empathetically and charitably towards the humanitarian causes that his images quietly champion.

Ultimately, the challenge for us as viewers seems to involve interpreting photographs in a way that allows us to cultivate our empathy, by consciously recognizing the obstacles to emotional identification that the medium of photography inherently imposes. Moreover, if we are users of camera phones, this would mean opting not to be, in Stuart Jeffries' words, 'snappers on autopilot, slaves to our machines', but instead to be more mindfully selective of our chosen photographic subjects before merrily snapping away. ${ }^{51}$ Barthes advises two ways to approach a photograph: either 'to subject its spectacle to the civilized code of perfect illusions', exposing it to the conceits of bourgeois society, or to 'confront in it the wakening of intractable reality', facing up to the undeniable horrors and trauma of the modern world. ${ }^{52}$ Perhaps we should pay closer attention to Carter's photograph again. This time we might just experience a keener emotional identification with both the suffering child and the photographer who was there with her, even while we realize our complicity as viewers who fuel the media's demand for images. In a sense, as consumers of photographs, we are the vultures gazing at others' sufferings, unless we choose to nurture our empathy and avoid the hazards of photographic objectification.

\section{Bibliography}

Ballard, J.G. "Some Words About Crash!". Foundation 9 (1975): 45-54.

Barthes, Roland. Camera Lucida. Translated by Richard Howard. New York: Hill and Wang, 1981. London: Vintage, 2000.

. "The Photographic Message." In A Barthes Reader, edited by Susan Sontag, 194-210. New York: Hill and Wang, 1983.

Baudrillard, Jean. Simulacra and Simulation. Translated by Sheila Glaser. Ann Arbor, MI: University of Michigan Press, 1981.

"empathy, n.". OED Online. 2014. Oxford University Press. Accessed 1 June 2014. http://www.oed.com/view/Entry/61284?redirectedFrom=empathy.

Fallows, James. "Are journalists people? How can they do their job while doing less harm." U.S. News \& World Report, 15 September 1997, 31-32, 34.

Hill, Geoffrey. "The Eloquence of Sober Truth." In Collected Critical Writings, edited by Kenneth Haynes, 328-48. Oxford: Oxford University Press, 2008.

Hulteng, John L. The Messenger's Motives: Ethical Problems of the News Media. Englewood Cliffs, NJ: Prentice-Hall, 1985.

"'I was gutted that I'd been such a coward': Photographers who didn't step in to help." Guardian. 2012. Accessed 1 June 2014. http://www.theguardian.com/media/2012/jul/28/gutted-photographerswho-didnt-help.

Jeffries, Stuart. "The rise of the camera-phone." Guardian. 8 January 2010. Accessed 1 June 2014. http://www.theguardian.com/technology/2010/jan/08/stuart-jeffries-camera-phones.

Keller, Bill. "Kevin Carter, a Pulitzer winner for Sudan photo, is dead at 33." New York Times, 29 July 1994, B8.

Kim Yung Soo and James D. Kelly, "Public Reactions toward an Ethical Dilemma Faced by Photojournalists: Examining the Conflict between Acting as a Dispassionate Observer and Acting as a 'Good Samaritan'," Journalism and Mass Communication Quarterly 87, no. 1 (2010): 23.

Kim, Yung Soo and James D. Kelly. "Photojournalist on the Edge: Reactions to Kevin Carter's Sudan Famine Photo." Visual Communication Quarterly 20, no. 4 (2013): 205-219. doi: $10.1080 / 15551393.2013 .849980$

\footnotetext{
51 "The rise of the camera-phone".

${ }^{52}$ Camera Lucida, 119.
} 
Kleinman, Arthur, and Joan Kleinman. "The Appeal of Experience; The Dismay of Images: Cultural Appropriations of Suffering in Our Times." Daedalus 125, no. 1 (1996): 1-23.

Lorch, Donatella. "Sudan Is Described as Trying to Placate the West." New York Times, 26 March 1993, A3.

Macleod, Scott. "The Life and Death of Kevin Carter." TIME 144, no. 11 (1994). Accessed 1 June 2014. http://content.time.com/time/magazine/article/0,9171,981431-1,00.html.

Marinovich, Greg and Joao Silva. The Bang-Bang Club: Snapshots from a Hidden War. New York: Basic Books, 2000.

McLuhan, Marshall. Understanding Media: The Extensions of Man. New York: McGraw-Hill, 1964.

O'Brien, Sue. "Eye on Soweto: A Study of Factors in News Photo Use." Journal of Mass Media Ethics 8, no. 2 (1993): 69-87.

Riper, Frank Van. "Pulitzer Pictures: Capturing the Moment". Washington Post. Accessed 17 October 2014. http://www.washingtonpost.com/wp-srv/photo/galleries/essays/001229.htm

Selwyn-Holmes, Alex. "Vulture Stalking a Child." Iconic Photos. 2009. Accessed 1 June 2014. http://iconicphotos.wordpress.com/2009/08/12/vulture-stalking-a-child/

Sontag, Susan. On Photography. London: Penguin, 1977.

. Regarding the Pain of Others. London: Penguin, 2003.

Stamets, Reena Shah. "Were his priorities out of focus?" St Petersburg Times (Florida), 14 April 1994, A1. 